\title{
Pharmacogenomic application of the haptoglobin genotype in the treatment of HDL dysfunction
}

\author{
Avery Schwartz \\ Shany Blum \\ Rabea Asleh \\ Mordechai Pollak \\ Shiri Kalet-Litman \\ Andrew P Levy \\ Department of Anatomy and Cell \\ Biology, Rappaport Faculty \\ of Medicine, Technion-Israel Institute \\ of Technology, Haifa, Israel
}

\begin{abstract}
An emerging paradigm of research has suggested that in the setting of diabetes mellitus (DM) the quality or function of high-density lipoprotein (HDL) may be a determinant of cardiovascular disease risk. Specific structural modifications of HDL protein and lipid components, resulting from oxidative modification, have been proposed to mediate HDL's loss of the ability to promote cholesterol efflux (reverse cholesterol transport), serve as an antioxidant and anti-inflammatory agent. Therefore, inhibiting HDL oxidative modification would be expected to improve its function and provide cardioprotection. Nevertheless, antioxidant strategies to reduce cardiovascular events from atherosclerosis in DM have failed. It has been proposed that this failure may have been due to the inadequate nature of patient selection. High dose antioxidant therapy may only provide benefit to a subset of DM individuals with oxidatively modified HDL. We will review evidence that haptoglobin (Hp) identifies such individuals who can be successfully treated with vitamin E. These data will suggest that a pharmacogenomic approach utilizing the Hp genotype may be useful in identifying individuals who will benefit from antioxidant therapy.
\end{abstract}

Keywords: diabetes, HDL, vitamin E, cardiovascular disease, oxidation

\section{Oxidative modification hypothesis of atherosclerosis}

Steinberg and associates first proposed that oxidative modification of low-density lipoprotein (LDL) may contribute to atherosclerosis by promoting macrophage infiltration and foam cell formation. ${ }^{1}$ The hypothesis has subsequently incorporated other oxidative events, such as high-density lipoprotein (HDL) oxidation, that paradoxically result in the ability of HDL to become dysfunctional and proatherogenic. ${ }^{2-4}$

\section{Dysfunctional HDL: Oxidative modification of HDL causes structural and functional changes making it proatherogenic}

Current paradigms regarding HDL and cardiovascular protection focus almost exclusively on HDL plasma concentration as a determinant of cardiovascular disease (CVD) risk. Accordingly, considerable effort has been expended in order to try to raise serum HDL levels. ${ }^{5}$ However, emerging research suggests that the quality or function of HDL may be a determinant of diabetes mellitus (DM; both type I and type II)-related CVD risk. ${ }^{2,5-10}$ Some propose HDL functionally prevents atherogenesis and atherothrombosis by (1) promoting cholesterol efflux (reverse cholesterol transport), (2) serving as an antioxidant, and (3) modulating inflammation (principally by destroying oxidized lipids derived from LDL which are proinflammatory). ${ }^{2,6,7,9}$ These functions are dependent on the preservation of HDL's structural integrity and composition. Research suggests that dysfunctional HDL production may be paradoxically pro-atherogenic., ${ }^{2,6,7}$ 
The structural modification of HDL has been shown to be achieved by two complementary mechanisms. The first is oxidative modification of protein (ie, Apo A1) and lipid components (cholesterol and long chain fatty acids) of HDL. The other being increased association of certain plasma proteins with HDL. ${ }^{2,6-9,11-17}$ Nonenzymatic glycation, found in DM, dramatically increases susceptibility of HDL protein components to oxidative modification. ${ }^{6,8,16}$ Changes in HDL structure, such as oxidatively modified ApoA1's interference with cholesterol efflux, have been shown to cause HDL dysfunction. ${ }^{2,6-8,11,12,14}$ When HDL loses its antioxidant activity, its subsequent lipid peroxidase accumulation paradoxically promotes the formation of LDL-derived oxidized lipids and inflammation. ${ }^{2}$

We have recently demonstrated that there is an increased association of hemoglobin with HDL in individuals with DM and defective HDL. ${ }^{18}$ We proposed that hemoglobin associated with HDL in the setting of DM, not only promotes oxidative modification of ApoA1 and lipid components of HDL, but also inactivates several key antioxidant enzymes associated with HDL such as lecithin cholesterol acyltransferase (LCAT), paraoxonase, and glutathione peroxidase. ${ }^{18}$

\section{Failure of antioxidants in clinical trials: Was the oxidative modification hypothesis wrong?}

Extensive preclinical studies driven by the oxidative modification hypothesis, demonstrated apparent benefit from vitamin $\mathrm{E}$ in the prevention of cardiovascular events, motivated many cardiologists to prescribe high doses of vitamin E. ${ }^{19}$ However, over the past 10 years, several prospective randomized clinical trials have reached the consensus that vitamin E supplementation does not provide cardiovascular benefit; ${ }^{20-29}$ to the contrary, meta-analysis of these studies has suggested that high dose vitamin E supplementation may increase mortality. Suspension of prescribed vitamin E has been called for in a number of opinion articles. ${ }^{28-31}$

Various reasons for the vitamin E antioxidant trials' failure, despite solid pre-clinical data, have been provided. Our compelling data suggests that the studies' failure to show benefit resulted from inadequate patient selection is one explanation. ${ }^{32}$ High dose antioxidant therapy may only provide benefit to individuals suffering from particularly high levels of oxidative stress. SPACE, ${ }^{33}$ a trial of vitamin $\mathrm{E}$ in hemodialysis patients who have very high levels of oxidative stress, supports this notion by demonstrating significant cardiovascular benefit from vitamin E. We recently demonstrated that the Hp genotyping may help to identify those patients with high levels of oxidative stress who may benefit from vitamin $\mathrm{E}$ antioxidant therapy. ${ }^{18,34,35}$

\section{The haptoglobin protein}

Haptoglobin (Hp) is an abundant plasma glycoprotein produced in the liver. ${ }^{36} \mathrm{Hp}$ 's best known function is to bind the 6-7 grams of free hemoglobin $(\mathrm{Hb})$ released daily from red blood cell turnover. Free $\mathrm{Hb}$ is capable of inflicting considerable oxidative tissue damage by releasing its heme iron. ${ }^{37-39} \mathrm{Hp}$, however, binds $\mathrm{Hb}$ with extremely high affinity inhibiting its heme iron release diminishing its oxidative potential. Blood Hp molar concentration normally exceeds free $\mathrm{Hb}$ molar concentration in excess of 400-fold (10 uM to $25 \mathrm{nM}$ ). Consequently, all $\mathrm{Hb}$ released after intravascular hemolysis is rapidly bound by Hp and rapidly cleared from the bloodstream via monocyte/ macrophage CD163 scavenger receptor. ${ }^{40-44}$

Comparisons of conflicting studies, as to whether Hp is an HDL-associated protein, suggests that the critical difference is in the HDL preparation. ${ }^{45-48}$ Vaisar and colleagues failed to demonstrate that Hp was a constituent of the HDL proteome when using HDL purified by repeated ultracentrifugation (UC). ${ }^{45}$ However, several different groups, including ours, have shown Hp to be a constituent of HDL when prepared by immunoabsorbtion or a one-step ultracentrifugation procedure. ${ }^{18,47,48} \mathrm{UC}$ not only changes the protein composition of HDL constituents, but also causes an apparent total loss of HDL-associated proteins. ${ }^{47}$ Focusing on the ultracentrifugation to purify HDL may obscure its natural association of many proteins.

While the significance of binding of Hp to HDL is unknown, we have suggested that Hp may compete with LCAT for a binding site on helix 6 of ApoA1, thereby decreasing LCAT function by its binding to HDL. ${ }^{46} \mathrm{We}$ found that Hp-bound HDL can tether Hb to HDL, thereby promoting the oxidative modification. ${ }^{18}$ Since $\mathrm{Hb}$ cannot directly bind HDL, their interaction is critically dependent on $\mathrm{Hb}$ 's binding to $\mathrm{Hp}$ which directly binds HDL. As discussed below, the association of $\mathrm{Hp}$ with HDL is critically dependent on DM and the Hp genotype.

\section{Polymorphism of the haptoglobin gene}

There are two classes of alleles ( 1 and 2) identified at the chromosome 16q22 Hp locus with homozygous (1-1 or $2-2$ ) and heterozygous (2-1) genotypes possible..$^{36,40}$ The Hp polymorphism is an extremely common polymorphism whose three genotype frequencies in the Western world are approximately 16\% Hp 1-1, 48\% Hp 2-1, and 36\% Hp 2-2 (the same in individuals with and without DM) ${ }^{36,40,49} \mathrm{Hp}$ does 
not determine susceptibility to DM, but rather it determines susceptibility to vascular complications in individuals with DM. The Hp 2 allele, present only in humans, appears to have arisen early in human evolution by a duplication of exons 3 and 4 in the Hp 1 allele. ${ }^{36,40}$ The Hp gene protein product (Hp monomer) is found in serum as a polymer of between 2-10 covalently linked monomers. The stoichiometry of the Hp polymer is genotype dependent because of differences in the valencies between the Hp 1 (monovalent) and the Hp 2 (bivalent) allelic protein products. Electron microscopy confirms that the Hp differences are dimerized Hp 1-1 individuals, linear polymerized Hp 2-1 individuals and cyclic polymerized Hp 2-2 individuals. ${ }^{50}$

Structural differences between the Hp types have profound importance not only for the interaction of $\mathrm{Hp}$ with $\mathrm{HDL}$, but also for the ability and amount of $\mathrm{Hb}$ that can be found tethered to HDL via Hp. The multimeric nature of the Hp 2 protein has a dramatically increased avidity for HDL. While single Hp 2-2 molecule may bind multiple ApoA1 molecules, an Hp 1-1 dimer may only bind to two ApoA1 molecules. In addition, the multimeric nature of $\mathrm{Hp} 2-2$ allows a single HDL-bound Hp 2-2 molecule to bind many times more $\mathrm{Hb}$ than a single HDL-bound Hp 1-1 molecule. The markedly greater amount of Hp associated with HDL in Hp 2-2 individuals as compared to Hp 1-1 individuals proves of this concept. ${ }^{18}$

\section{Epidemiological studies showing that the Hp 2-2 genotype is a major determinant of susceptibility to diabetic CVD in man}

We and others have established in multiple independent prospective longitudinal studies of over 30,000 individuals that the Hp genotype is an independent risk factor for incident CVD and that this relationship is specific for DM. ${ }^{35,51-54}$ After controlling for all conventional cardiac risk factors and DM characteristics in all of these studies, we have consistently found that there is a 2-5-fold increased risk of CVD among DM individuals with the Hp 2-2 genotype (Table 1). The Hp 2-2 genotype appears to account for a large portion of the increased DM-associated CVD burden which has heretofore been unexplainable.

\section{HDL function is impaired in Hp 2-2 DM mice and humans}

We have assessed the ability of serum from Type I and Type II DM individuals with the different Hp types to promote in vitro ${ }^{3} \mathrm{H}$-cholesterol efflux from macrophages and have observed a significantly decreased efflux from macrophages incubated with serum from Hp 2-2 DM individuals. ${ }^{18}$ This was recapitulated using serum from $\mathrm{Hp}$ 2-2 DM mice as compared to Hp 1-1 DM mice. ${ }^{18}$ No differences in cholesterol efflux were seen in mice or humans with the different Hp genotypes in the absence of DM. We have also assessed reverse cholesterol transport in vivo using a model, recently described by Rader, ${ }^{55}$ involving injection of ${ }^{3} \mathrm{H}$-cholesterol-loaded macrophages and monitoring the appearance of the tracer in the plasma, feces, and liver. We found that DM mice loaded with ${ }^{3} \mathrm{H}$-cholesterolabeled macrophages showed a $40 \%$ reduction of ${ }^{3} \mathrm{H}$-cholesterol in plasma, liver,and feces compared to non-DM mice. ${ }^{56}$

\section{Increased lipid peroxides in the HDL of Hp 2-2 DM individuals and mice}

We have assessed the amount of lipid peroxides in HDL isolated from Hp 1-1 or Hp 2-2 DM individuals and mice, and have found that lipid peroxides were significantly increased in the HDL of Hp 2-2 DM mice and humans. ${ }^{18}$ This increase in oxidized lipids in Hp 2-2 DM may be attributed to a decrease in the antioxidant activity of enzymes associated with HDL (ie, glutathione peroxidase or paraoxonase) and an increase in the amount of hemoglobin derived redox active iron associated with HDL. ${ }^{18}$

\section{Mechanistic studies demonstrating why there is an increased association of $\mathrm{Hp}-\mathrm{Hb}$ with HDL in Hp 2-2 DM individuals}

We have hypothesized that the direct association of the Hp 2-2-Hb complex with HDL results in an Hp 2-2 genotype interaction with DM to promote HDL oxidative modification and dysfunction (Figure 1). ${ }^{18} \mathrm{Hb}$ is released by hemolysis from red blood cells and is rapidly complexed by Hp. CD163 is the $\mathrm{Hp}-\mathrm{Hb}$ scavenger receptor on monocyte/macrophages and is believed to play a predominant role in scavenging $\mathrm{Hp}-\mathrm{Hb}$ complexes by receptor-mediated endocytosis. ${ }^{43}$ We demonstrated that the $\mathrm{Hp} 1-1-\mathrm{Hb}$ complex is cleared more efficiently and rapidly by the CD163 receptor than the Hp 2-Hb complex. ${ }^{18}$ Consequently, a slower clearance rate of $\mathrm{Hp} 2-\mathrm{Hb}$ complex from the plasmatic compartment results in a higher steady state $\mathrm{Hp}-\mathrm{Hb}$ complex serum concentration as demonstrated in Hp 2 DM mice.

As discussed above, $\mathrm{Hp}$ can bind to HDL (via a site on Apo A1) and more Hp protein is associated with HDL in Hp 2-2 
Table I Summary of longitudinal studies of individuals with DM demonstrating increased incidence of CVD associated with the HP 2-2 genotype

\begin{tabular}{|c|c|c|c|}
\hline Study & \# DM participants & Study endpoint & Outcomes \\
\hline Strong Heart Study ${ }^{51}$ & Nested case control & CVD & 3-5-fold increase risk in $\mathrm{Hp} 2-2$ vs non-Hp 2-2 \\
\hline Rambam $^{53}$ & 506 & Death/CHF 30 days after $\mathrm{MI}$ & 8-fold increase in $\mathrm{Hp} 2-2$ vs $\mathrm{Hp} \mathrm{I}-\mathrm{I}$ \\
\hline Munich ${ }^{52}$ & 935 & MACE in $\mathrm{I}$-year period after $\mathrm{PCl}$ & 2-fold increased $\mathrm{MI}$ in $\mathrm{Hp} 2-2$ vs non-Hp 2-2 \\
\hline $\mathrm{EDC}^{54}$ & 453 & CAD & $\begin{array}{l}\text { 2-fold increase in } \mathrm{Hp} 2-2 \text { vs } \mathrm{Hp} \mathrm{I}-\mathrm{I} \text {; intermediate } \\
\text { risk in } \mathrm{Hp} 2-\mathrm{I}\end{array}$ \\
\hline ICARE $^{35}$ & 3054 & $\begin{array}{l}\text { Composite of MI, stroke, } \\
\text { and cardiovascular death }\end{array}$ & 2-fold increase in Hp 2-2 vs non-Hp 2-2 \\
\hline
\end{tabular}

Abbreviations: CAD, coronary artery disease; CHF, congestive heart failure; CVD, cardiovascular disease; DM, diabetes mellitus; EDC, Pittsburgh Epidemiology of Diabetes Complications study; ICARE, Israel Cardiovascular Events Reduction with Vitamin E study; MACE, major adverse cardiovascular events; MI, myocardial infarction; PCI, percutaneous coronary intervention.

individuals than in Hp 1-1 individuals. The increased amount of Hp bound per HDL in Hp 2-2 is important because each Hp monomer which is bound to HDL provides a potential binding site for $\mathrm{Hb}$. We assessed the presence of $\mathrm{Hb}$ in $\mathrm{HDL}$ by western blot, immunoprecipitated with ApoA1 antiserum from Hp 1-1 or Hp 2-2 genotype individuals with and without DM. While we were unable to detect $\mathrm{Hb}$ by western blot in individuals without DM, or in Hp 1-1 genotype DM individuals, we did observe $\mathrm{Hb}$ in the HDL of nearly all $\mathrm{Hp} 2-2$ genotype individuals with DM. This specific association was recapitulated in mice. ${ }^{18}$

Hp-1 Genotype

Preserved HDL Function

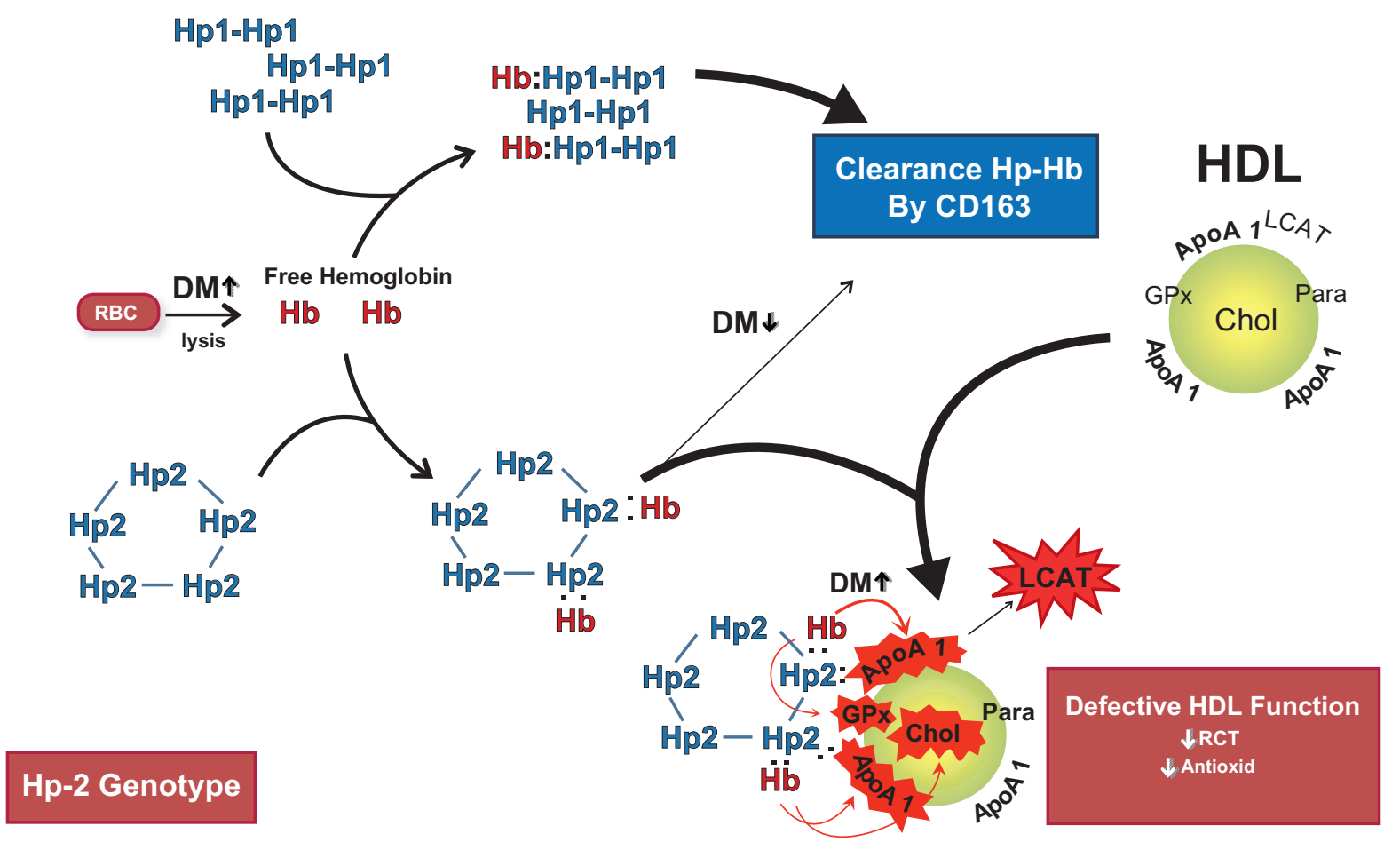

Figure I Hemoglobin $(\mathrm{Hb})$ released intravascularly from red blood cells $(\mathrm{RBC})$ is rapidly bound by haptoglobin $(\mathrm{Hp})$ protein to form an $\mathrm{Hp}-\mathrm{Hb}$ complex. In $\mathrm{Hp} 2$ diabetes mellitus (DM) individuals the complex is cleared more slowly than in $\mathrm{Hp}$ I DM individuals by the scavenger receptor CD I63.The Hp-Hb complex can bind to Apo AI in highdensity lipoprotein (HDL), with increased binding of $\mathrm{Hp} 2-\mathrm{Hb}$ occurring due its increased avidity for $\mathrm{HDL}$ and its increased plasma concentration. The $\mathrm{Hp} 2-\mathrm{Hb}$, but not the $\mathrm{Hp} \mathrm{I-Hb} \mathrm{complex,} \mathrm{when} \mathrm{bound} \mathrm{to} \mathrm{HDL} \mathrm{can} \mathrm{produce} \mathrm{reactive} \mathrm{oxygen} \mathrm{species} \mathrm{which} \mathrm{can} \mathrm{oxidize} \mathrm{protein} \mathrm{(ie,ApoAI;} \mathrm{GPx-glutathione} \mathrm{peroxidase;} \mathrm{LCAT)} \mathrm{and} \mathrm{lipid} \mathrm{components}$ (cholesterol) of HDL and render the HDL dysfunctional (due to decreased reversed cholesterol transport [RCT] and antioxidant activity) proatherogenic and prothrombotic. Copyright (C) 2008. Reproduced with permission from Asleh R, Blum S, Kalet-Litman S, et al Correction of HDL dysfunction in individuals with diabetes and the haptoglobin 2-2 genotype. Diabetes. 2008; 57:2794-2800. 


\section{Increased oxidant activity and redox active iron associated with the HDL of Hp 2-2 DM individuals}

We have proposed that $\mathrm{Hb}$-derived iron associated with the HDL in Hp 2-2 DM individuals increases oxidative modification of HDL-associated lipids and proteins. We sought to demonstrate an increase in the amount of redox activity attributable to iron associated with HDL in $\mathrm{Hp}$ 2-2 DM individuals. HDL redox activity was determined by measuring the time dependent oxidation of dihydrorhodamine (DHR) which becomes fluorescent as it oxidizes. ${ }^{57}$ Oxidation reactions were performed in the presence and absence of the iron chelator deferiprone (L1) in order to determine the importance of iron in DHR oxidation. ${ }^{57} \mathrm{We}$ found that Hp 2-2 DM individuals had markedly greater HDL-mediated oxidation than Hp 1-1 DM individuals. ${ }^{18}$ Based on the difference in the slope of the DHR oxidation curve in the presence and the absence of the iron chelator and a standard curve for iron-induced DHR oxidation, we calculated the total amount of labile iron in the HDL preparation from each patient which found significantly more redox active chelatable iron in the HDL of Hp 2-2 DM individuals than individuals with Hp 1-1 DM. The increased redox active chelatable iron in Hp 2-2 DM HDL may be responsible for the increased oxidation of HDL associated lipids and proteins in Hp 2-2 DM HDL and is therefore why Hp 2-2 DM individuals may uniquely benefit from antioxidant therapy, as we will discuss below.

\section{Proof that the increased HDL dysfunction and poor CV outcomes in Hp 2-2 DM is due to increased oxidant stress}

The combined insult of increased prooxidative activity from $\mathrm{Hb}$ and decreased antioxidative activity associated with $\mathrm{HDL}$, in Hp 2-2 DM individuals, have resulted in our hypothesis that Hp 2-2 DM individuals have increased oxidative modification of HDL. ${ }^{18}$ Given that oxidative modification of HDL may inhibit its function, we hypothesized that supplementing Hp 2-2 DM mice or humans with antioxidants would improve HDL function.

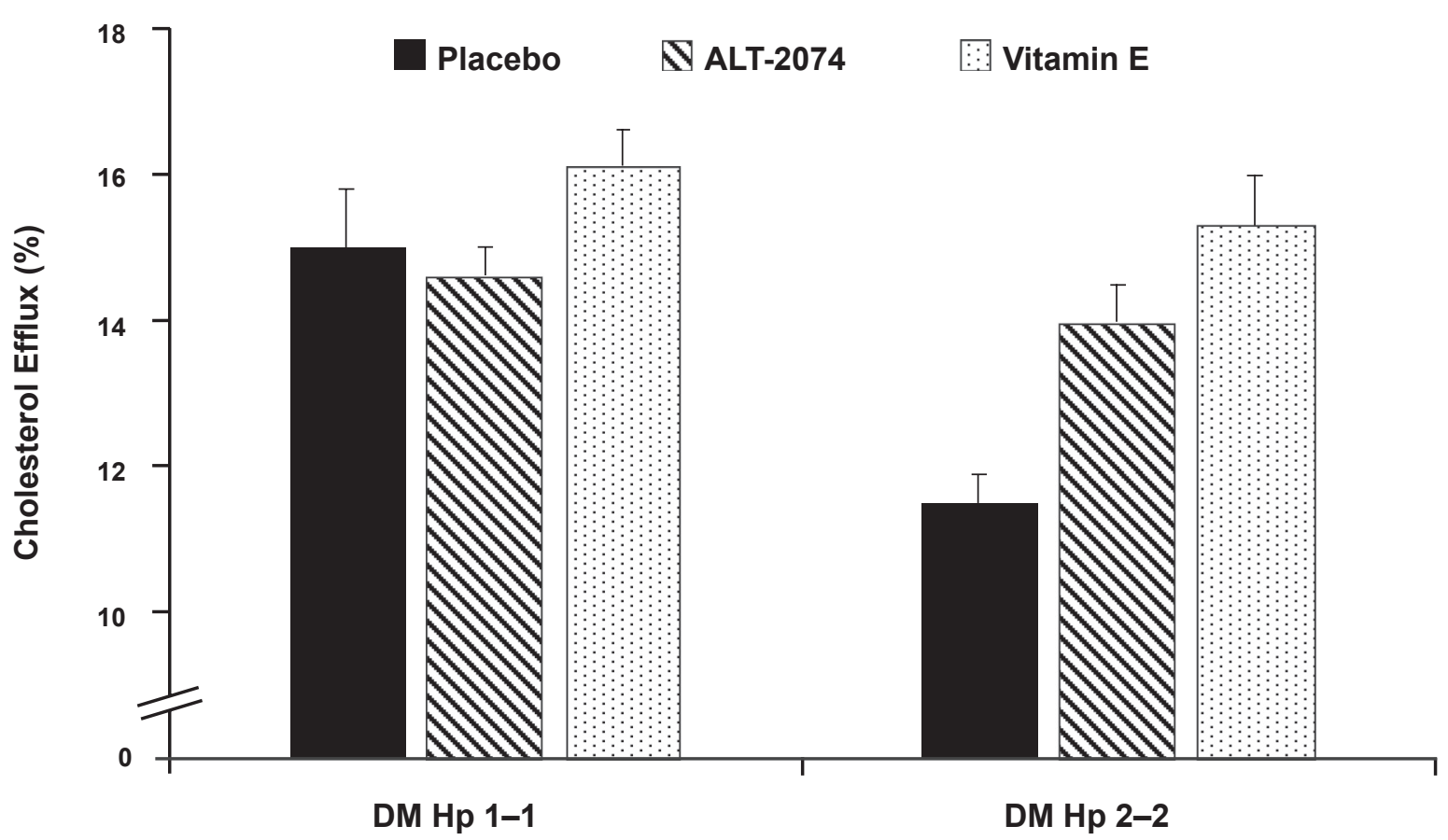

Figure 2 Antioxidant treatment improves the ability of serum of $\mathrm{Hp} 2-2$ diabetes mellitus (DM) mice, but not Hp I-I DM mice, to promote cholesterol efflux from macrophages. Hp I-I or Hp 2-2 DM mice were treated for 28 days with either placebo,ALT-2074, a synthetic glutathione peroxidase mimic at a dose of $2 \mathrm{mg} / \mathrm{kg} /$ day, or vitamin E, alpha-tocophorol at $40 \mathrm{mg} / \mathrm{kg} / \mathrm{day}$. In mice without DM there was no difference in efflux elicited by serum from Hp I or Hp 2 mice ( $\mathrm{p}=0.50)$ (data not shown). However, in the presence of DM there was a significant difference between $\mathrm{Hp} \mathrm{I-I} \mathrm{and} \mathrm{Hp} \mathrm{2-2} \mathrm{DM} \mathrm{mice}(\mathrm{P}=0.002)$. Both alanine transferase (ALT) and vitamin E significantly improved cholesterol efflux in Hp 2-2 DM mice ( $p=0.002$ comparing $\mathrm{Hp} 2-2 \mathrm{P}$ vs ALT and $p=0.0006$ comparing Hp 2-2 P vs vitamin E). Moreover, after ALT or vitamin $E$ treatment efflux elicited by the serum of $\mathrm{Hp} 2-2 \mathrm{DM}$ mice was not significantly different from that elicited by $\mathrm{HP}$ I-I DM mice. Neither ALT nor vitamin E had any effect on efflux in HP I-I DM mice $(p=0.63$ for ALT and $p=0.29)$. 
We treated Hp 1-1 and Hp 2-2 DM mice for 28 days with placebo or vitamin E $(600 \mathrm{mg} / \mathrm{kg} / \mathrm{d})$. Although cholesterol efflux elicited by serum of Hp 2-2 DM mice was significantly impaired compared to the efflux elicited by the serum from Hp 1-1 DM mice the vitamin E significantly improved cholesterol efflux in Hp 2-2 DM mice but had no effect on HDL function in Hp 1-1 DM mice, thereby demonstrating a pharmacogenomic effect (Figure 2). ${ }^{18}$ These data suggest that an oxidative mechanism causes an impairment in cholesterol efflux elicited by Hp 2 DM serum.

We also administered vitamin E (400 IU/day) or placebo to Hp 2-2 DM individuals in a double-blind crossover study. ${ }^{18}$ Serum was collected at baseline, after the first two months of treatment with either vitamin $\mathrm{E}$ or placebo and again after an additional two months of the opposite treatment (placebo or vitamin). We found that vitamin E dramatically improved Hp 2-2 DM serum's ability to mediate efflux of cholesterol in vitro. No change in efflux was found in the placebo group and importantly withdrawing vitamin $\mathrm{E}$ for as little as two months resulted in a loss of the beneficial effects of vitamin E (Figure 3$){ }^{18}$

\section{Vitamin E reduces CVD events in Hp 2-2 DM individuals}

We have demonstrated in two clinical studies that vitamin E results in a dramatic reduction in CVD events in Hp 2-2 DM individuals. ${ }^{35,58}$ The HOPE study found no benefit from vitamin E supplementation. ${ }^{59}$ In determining the relative risk reduction associated with vitamin E therapy according to Hp type in patients with and without DM, we found that in Hp 2-2 DM participants vitamin E reduced CV death and non-fatal MI. ${ }^{58}$ In the ICARE study, (a prospective study comparing vitamin $\mathrm{E}$ vs placebo on the combined outcome of $\mathrm{CV}$ death, stroke and $\mathrm{MI}$ in a primary care setting) we found that vitamin E reduced the primary outcome by over $50 \% .{ }^{35}$ These studies suggest that a pharmacogenomic approach may be useful in identifying a large subgroup of DM individuals who can potentially derive cardiovascular benefit from a very inexpensive treatment.

\section{Significance, health relevance, and future directions}

We have presented a pharmacogenomic mechanism for the apparent failure of antioxidant therapy to demonstrate any cardiovascular benefit in over 20 major clinical trials, while demonstrating considerable benefit when targeted to DM individuals with the Hp 2-2 genotype. DM individuals with the Hp 2-2 genotype may benefit from an extremely safe and inexpensive therapy that can reduce $\mathrm{CV}$ death, myocardial infarction, and stroke. We have provided one mechanism for this pharmacogenomic effect of vitamin $\mathrm{E}$ as it is mediated thru HDL function. We are proposing a personalized approach to medical care by enabling identification of the individuals who will benefit from vitamin E supplementation based on their Hp genotype. However, it is clear that in order for this pharmacogenomic paradigm to reach the clinic, it will be necessary to perform an additional large scale prospective pharmacogenomic study examining the interaction between Hp genotype and vitamin E on CVD in individuals with DM. As an illustration of the difficulty involved in
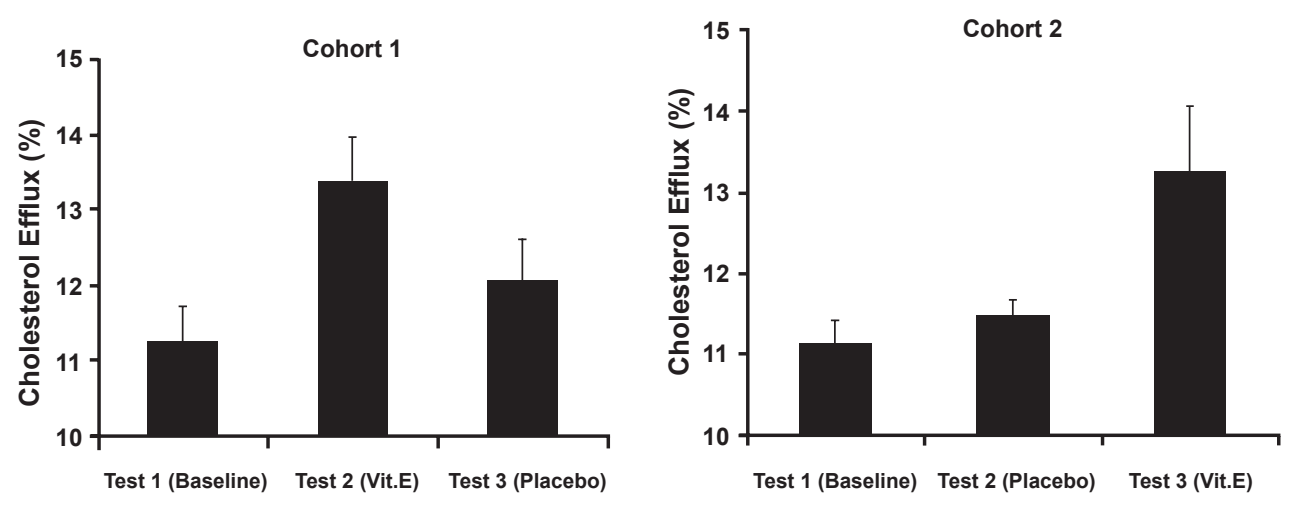

Figure 3 Improvement in cholesterol efflux stimulated by $\mathrm{Hp} 2-2$ serum with vitamin E in man. Crossover design placebo-controlled double-blind trial. $20 \mathrm{Hp} 2-2$ individuals divided into two cohorts were randomized to either vitamin $\mathrm{E}$ or placebo and treated for two months. After a two-week washout, patients were crossed over to the other treatment and treated for an additional two months. Blood samples were taken at baseline (test I), after two months of the initial treatment (test 2 ) or after two months with the second treatment (test 3 ). There was a significant improvement in efflux with vitamin $\mathrm{E}$ treatment (test $\mathrm{I}$-test 2 in cohort $\mathrm{I}, \mathrm{p}=0.004$; test 2 -test 3 in cohort 2 , $\mathrm{P}=0.04$ ) and no change with placebo treatment (test $\mathrm{I}$-test 2 in cohort $2, \mathrm{P}=0.33$ ). Of note in cohort $\mathrm{I}$, test 3 is not significantly different from the baseline value demonstrating that even though vitamin $\mathrm{E}$ improved high-density lipoprotein (HDL) function after a two-month period (compare test I-test 2) after a two-month washout with placebo HDL function returned to baseline levels. Copyright @ $200 \mathrm{I}$. Reproduced with permission from Asleh R, Blum S, Kalet-Litman S, et al Correction of HDL dysfunction in individuals with diabetes and the haptoglobin 2-2 genotype. Diabetes. 2008; 57:2794-2800. 
such a pharmacogenomic study, achieving an $80 \%$ power to demonstrate a significant interaction between Hp genotype (Hp 2-2 vs non-Hp 2-2) and vitamin E on CVD risk would require 15,000 individuals over a period of three years. The pharmacogenomic paradigm's public health implications, both in terms of saving lives and reducing costs, suggests that an investment in such a study would be prudent even in the current fiscal state of affairs. Furthermore, as DM prevalence continues to increase at an alarming rate the medications used to prevent diabetes induced complications are neither accessible nor affordable to many populations. Vitamin E, however, is inexpensive enough such that it can be made available to all populations, worldwide. Furthermore, with the recent development of an ELISA-based assay for Hp typing the technological requirements for determining $\mathrm{Hp}$ type are extremely simple.

\section{Acknowledgments}

This work was funded by the Israel Science Foundation, The US Israel Binational Science Foundation, the Kennedy Leigh Charitable Trust and the Juvenile Diabetes Research Foundation all to APL.

\section{Disclosure}

Dr Levy is a consultant for Synvista Therapeutics, which owns a patent for Hp testing.

\section{References}

1. Steinberg D, Parthasarathy S, Carew TE, Khoo JC, Witztum JL. Beyond cholesterol: modifications of low-density lipoprotein that increase its atherogenicity. N Engl J Med. 1989;320(14):915-924.

2. Navab M, Anantharamaiah GM, Reddy ST, Van Lenten BJ, Ansell BJ, Fogelman AM. Mechanisms of Disease: proatherogenic HDL-an evolving field. Nature Clin Pract Endocrinol Metab. 2006;2(9):504-511.

3. Stocker R, Keaney JF. Role of oxidative modifications in atherosclerosis. Physiol Rev. 2004;84(4):1381-1478.

4. Stocker R, Keaney JF. New insights on oxidative stress in the artery wall. J Thromb Haemost. 2005;3(8):1825-1834.

5. Rader DJ. Molecular regulation of HDL metabolism and function: implications for novel therapies. J Clin Invest. 2006;116(12):3090-3100.

6. Kontush A, Chapman MJ. Functionally defective high density lipoprotein: a new therapeutic target at the crossroads of dyslipidemia, inflammation, and atherosclerosis. Pharmacol Rev. 2006;58(3): 342-374.

7. Ferretti G, Bacchetti T, Negre-Salvayre A, Salvayre R, Dousset N, Curatola G. Structural modifications of HDL and functional consequences. Atherosclerosis. 2006;184(1):1-7.

8. Norata GD, Pirillo A, Catapano AL. Modified HDL: Biological and physiopathological consequences. Nutr Metab Cardiovasc Dis. 2006;16(5):371-386.

9. Watanabe J, Chou KJ, Liao JC, et al. Differential association of hemoglobin with proinflammatory high density lipoproteins in atherogenic/hyperlipidemic mice. J Biol Chem. 2007;282(32):23698-23707.

10. Groop FH, Thomas MC, Rosenbard-Barlund M, et al. HDL composition predicts new onset cardiovascular disease in patients with Type I diabetes. Diabetes Care. 2007;30(10):2706-2707.
11. Wu Z, Wagner MA, Zheng L, et al. The refined structure of nascent HDL reveals a key functional domain for particle maturation and dysfunction. Nat Struct Mol Biol. 2007;14(9):861-868.

12. Shao B, Oda MN, Vaiser T, Oram JF, Heinecke JW. Pathways for oxidation of high-density lipoprotein in human cardiovascular disease. Curr Opin Mol Ther. 2006;8(3):198-205.

13. Anantharamaiah GM, Mishra VK, Garber DW, et al. Structural requirements for antioxidative and anti-inflammatory properties of apolipoprotein A-1 mimetic peptides. J Lipid Res. 2007;48(9): 1915-1923.

14. Shao B, Oda MN, Bergt C, et al. Myeloperoxidase impairs ABCA1dependent cholesterol efflux through methionine oxidation and site-specific tyrosine chlorination of apolipoprotein A-1.J Biol Chem. 2006;281(14):9001-9004

15. Blum CB, Levy RI, Eisenberg S, Hall M, Goebel RH, Berman M. High density lipoprotein metabolism in man. J Clin Invest. 1977;60(4): 795-807.

16. Nobecourt E, Davies MJ, Brown BE, et al. The impact of glycation on apolipoprotein A-1 structure and its ability to activate lecithin: cholesterol acyltransferase. Diabetologia. 2007;50(3):643-653.

17. Alexander ET, Bhat S, Thomas MJ, et al. Apolipoprotein A-1 helix 6 negatively charged residues attenuate lecithin-cholesterol acyltransferase (LCAT) reactivity. Biochemistry. 2005;44(14):5409-5419.

18. Asleh R, Blum S, Kalet-Litman S, et al. Correction of HDL dysfunction in individuals with diabetes and the haptoglobin 2-2 genotype. Diabetes. 2008;57(10):2794-2800.

19. Vivekananthan DP, Penn MS, Sapp SK, Hsu A, Topol EJ. Use of antioxidant vitamins for the prevention of cardiovascular disease: metaanalysis of randomized trials. Lancet. 2003;361(9374):2017-2023.

20. Lonn E, Bosch J, Yusuf S, Sheridan P, et al; HOPE and HOPE-TOO Trial Investigators. Effects of long-term vitamin E supplementation on cardiovascular events and cancer. JAMA. 2005;293(11):1338-1347.

21. Yusuf S, Dagenais G, Pogue J, Bosch J, Sleight P. Vitamin E supplementation and cardiovascular events in high-risk patients. The Heart Outcomes Prevention Evaluation Study Investigators. $N$ Engl $J$ Med. 2000;342(3):154-160.

22. Heart Protection Study Collaborative Group. MRC/BHF Heart Protection Study of antioxidant vitamin supplementation in 20,536 high risk individuals; a randomized placebo controlled trial. Lancet. 2002;360(9326):23-33.

23. Waters DD, Alderman EL, Hsia J, et al. Effects of hormone replacement therapy and antioxidant vitamin supplements on coronary atherosclerosis in postmenopausal women: a randomized controlled trial. JAMA. 2002;288(19):2432-2440

24. de Gaetano G; Collaborative Group of the Primary Prevention Project. Low-dose aspirin and vitamin $\mathrm{E}$ in people at cardiovascular risk: a randomised trial in general practice. Collaborative Group of the Primary Prevention Project. Lancet. 2001;357(9250):89-95.

25. Dietary supplementation with $n-3$ polyunsaturated fatty acids and vitamin E after myocardial infarction: results of the GISSI-Prevenzione trial. Gruppo Italiano per lo Studio della Sopravvivenza nell'Infarto miocardico. Lancet. 1999;354(9177):447-455.

26. Stephens NG, Parsons A, Schofeld PM, Kelly F, Cheeseman K, Mitchinson MJ. Randomized controlled trial of vitamin E in patients with coronary disease: Cambridge Heart Antioxidant Study (CHAOS). Lancet. 1996;347(9004):781-786.

27. Lee IM, Cook NR, Gaziano JM, Gordon D, Ridker PM, Manson JE, Hennekens CH, Buring JE. Vitamin E in the primary prevention of cardiovascular disease and cancer. The Women's Health Study: a randomized controlled trial. JAMA. 2005;294(1):56-65.

28. Brown BG, Crowley J. Is there any hope for vitamin E? JAMA. 2005;293(11):1387-1390.

29. Redberg RF. Vitamin E and cardiovascular health. JAMA. 2005; 294(1):107-109.

30. Miller ER, Barriuso RP, Dalal D, Riemersma RA, Appel LJ, Guallar E. Meta-analysis: high-dosage vitamin E supplementation may increase all-cause mortality. Ann Intern Med. 2005;142(1):37-46. 
31. Bjelakovic G, Nikolova D, Gluud LL, Simonetti RG, Gluud C. Mortality in randomized trials of antioxidant supplements for primary and secondary prevention: systematic review and meta-analysis. JAMA. 2007;297(8):842-857.

32. Steinberg D, Witztum JL. Is the oxidative modification hypothesis relevant to human atherosclerosis? Do the antioxidant trials conducted to date refute the hypothesis? Circulation. 2002;105(17):2107-2111.

33. Boaz M, Smetana S, Weinstein $\mathrm{T}$, et al. Secondary prevention with antioxidants of cardiovascular disease in endstage renal disease (SPACE): randomized placebo controlled trial. Lancet. 2000;356(9237): 1213-1218.

34. Blum S, Milman U, Shapira C, Levy AP. Pharmacogenomic application of the haptoglobin genotype in the prevention of diabetic cardiovascular disease. Pharmacogenomics. 2008;9(8):989-991.

35. Milman U, Blum S, Shapira C, et al. Vitamin E supplementation reduces cardiovascular events in a subgroup of middle-aged individuals with both Type 2 Diabetes Mellitus and the Haptoglobin 2-2 genotype: a prospective, double-blinded clinical trial. Arterioscler Thromb Vasc Biol. 2008;28(2):341-347.

36. Bowman BH, Kurosky A. Haptoglobin: the evolutionary product of duplication, unequal crossing over, and point mutation. Adv Hum Genet. 1982;12:189-261

37. Melamed-Frank M, Lache O, Enav BI, et al. Structure-function analysis of the antioxidant properties of haptoglobin. Blood. 2001;98(13):3693-3698.

38. Miller YI, Altamentova SM, Shaklai N. Oxidation of low-density lipoprotein by hemoglobin stems from a heme-initiated globin radical: antioxidant role of haptoglobin. Biochemistry. 1997;36(40):12189-12198.

39. Bamm VV, Tsemakhovich VA, Shaklai M, Shaklai N. Haptoglobin phenotypes differ in their ability to inhibit heme transfer from hemoglobin to LDL. Biochemistry. 2004;43(13):3899-3906.

40. Langlois MR, Delanghe JR. Biological and clinical significance of haptoglobin polymorphism in humans. Clin Chem. 1996;42(10):1589-1600.

41. Garby L, Noyes WD. Studies on hemoglobin metabolism. The kinetic properties of the plasma hemoglobin pool in normal man. J Clin Invest. 1959;38:1479-1483.

42. Hershko C. The fate of circulating hemoglobin. Br J Haematol. 1975;29(2):199-204.

43. Kristiansen M, Graversen JH, Jacobsen C, Sonne O, Hoffman HJ, Law SK, Moestrup SK. Identification of the hemoglobin scavenger receptor. Nature. 2001;409(6817):198-201.

44. Graversen JH, Madsen M, Moestrup SK. CD163: a signal receptor scavenging haptoglobin hemoglobin complexes from plasma. Int $J$ Biochem Cell Biol. 2002;34(4):309-314.

45. Vaisar T, Pennathur S, Green PS, et al. Shotgun proteomics implicates protease inhibition and complement activation in the anti-inflammatory properties of HDL. J Clin Invest. 2007;117(3):746-756.
46. Spagnuolo MS, Cigliano L, D'Andrea LD, Pedone C, Abrescia P. Assignment of the binding site for haptoglobin on apolipoprotein A-1. J Biol Chem. 2005;280(2):1193-1198.

47. Kunitake ST, Carilli CT, Lau K, Protter AA, Naya-Vigne J, Kane JP. Identification of proteins associated with apolipoprotein A-1 containing lipoproteins purified by selected-affinity immunosorbtion. Biochemistry. 1994;33(8):1988-1993.

48. Rezaee F, Casetta B, Levels JH, Speijer D, Meijers JCM. Proteomic analysis of high density lipoprotein. Proteomics. 2006;6(2):721-730.

49. Awadallah S, Hamad M. The prevalence of type II diabetes mellitus is haptoglobin phenotype independent. Cytobios. 2000;101(398):145-150.

50. Wejman JC, Hovsepian D, Wall JS, Hainfeld JF, Greer J. Structure and assembly of haptoglobin polymers by electron microscopy. $\mathrm{J} \mathrm{Mol} \mathrm{Biol.}$ 1984;174(2):343-368.

51. Levy AP, Hochberg I, Jablonski K, et al; Strong Heart Study. Haptoglobin phenotype is an independent risk factor for cardiovascular disease in individuals with diabetes: The Strong Heart Study. J Am Coll Cardiol. 2002;40(11):1984-1990.

52. Roguin A, Koch W, Kastrati A, Aronson D, Schomig A, Levy AP. Haptoglobin genotype is predictive of major adverse cardiac events in the one year period after PTCA in individuals with diabetes. Diabetes Care. 2003;26(9):2628-2631.

53. Suleiman M, Aronson D, Asleh R, et al. Haptoglobin polymorphism predicts 30-day mortality and heart failure in patients with diabetes and acute myocardial infarction. Diabetes. 2005;54(9):2802-2806.

54. Costacou T, Ferrell RE, Orchard TJ. Haptoglobin genotype: a determinant of cardiovascular complication risk in Type I diabetes. Diabetes. 2008;57(6):1702-1706.

55. Zhang Y, Zanotti I, Reilly MP, Glick JM, Rothblat GH, Rader DJ. Overexpression of apolipoprotein A-I promotes reverse transport of cholesterol from macrophages to feces in vivo. Circulation. 2003;108(6):661-663.

56. Asleh R, Miller-Lotan R, Aviram M, et al. Haptoglobin genotype is a regulator of reverse cholesterol transport in diabetes in vitro and in vivo. Circ Res. 2006;99(12):1419-1425.

57. Asleh R, Guetta J, Kalet-Litman S, Miller-Lotan R, Levy AP. Haptoglobin genotype and diabetes dependent differences in iron mediated oxidative stress in vitro and in vivo. Circ Res 2005;96(4):435-441.

58. Levy AP, Gerstein H, Miller-Lotan R, et al. The effect of vitamin E supplementation on cardiovascular risk in diabetic individuals with different haptoglobin phenotypes. Diabetes Care. 2004;27(11):2767.

59. Yusuf S, Dagenais G, Pogue J, Bosch J, Sleight P. Vitamin E supplementation and cardiovascular events in high risk patients. The Heart Outcomes Prevention Evaluation Study Investigators. $N$ Engl J Med. 2000;342(3):154-160. 